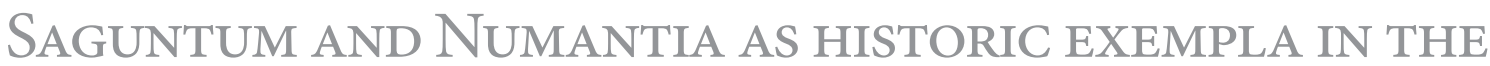 SPANISH PARLIAMENTARY ORATORY FROM 1868 TO 1939 Sagunto y Numancia como exempla históricos en la oratoria parlamentaria de la España liberal $(1868-1939)$
}

\section{Pepa Castillo}

\section{Universidad de La Rioja}

mariajose.castillo@unirioja.es

Fecha recepción 01.02.2016 / Fecha aceptación 20.11.2017

\section{Resumen}

En el s. XIX España necesitaba consolidar su identidad nacional y para ello era necesario fijar los rasgos que definían el carácter y temperamento de la raza española. En este contexto, personajes y gestas del pasado remoto de España eran los que mejor podían reflejar la idiosincrasia de la emergente nación. Una de esas gestas fue la que protagonizaron los habitantes de Sagunto y de Numancia, dos ciu-

\begin{abstract}
In the $19^{\text {th }}$ century, Spain sought to consolidate its national identity. To bear this out, it had to fix the traits that defined the character and temperament of the Spanish people. In this context, what best reflected the idiosyncrasy of the emerging nation were the personalities and the heroic feats of the remote past of Spain. Such was the case of the deeds carried out by the inhabitants of Sagun-
\end{abstract}

* Este artículo ha sido escrito en mi calidad de investigador colaborador del Proyecto Antigüedad, nacionalismos e identidades en la historiografía occidental (1700 - 1900): los casos español, británico y argentino (MINECO HAR2012-31746, IP Antonio Duplá Ansuátegui). 
Miscelánea | Sagunto y Numancia como exempla históricos en la oratoria parlamentaria de la España liberal (1868 - 1939)

dades que simbolizaban la lucha heroica de todo un pueblo por su libertad e independencia. En este artículo se analiza el uso que se hace de Sagunto y Numancia en los discursos que se pronunciaron en el Congreso de los Diputados desde la Revolución de 1868 hasta el 2 de febrero de 1939, última reunión de las Cortes en territorio español.

\section{Palabras clave}

Sagunto. Numancia. Oratoria política. Exempla históricos. tum and Numantia, two cities which symbolized the heroic struggle of a people for their freedom and independence. This paper analyses the use of Saguntum and Numantia as historic exempla in the speeches delivered to the Congress of Deputies between the Glorious Revolution of 1868 and 2 February 1939, the day the courts met in Spanish territory for the last time.

\section{Keywords}

Saguntum. Numantia. Political oratory. Historic exempla. 
Aunque SE PUede AFIRMAR QUe A FINALES Del Siglo XVIII ya se habían establecido las bases de una identidad nacional, hay que esperar a la siguiente centuria para que este sentimiento se extienda y sea aceptado por la mayor parte de los habitantes del nuevo estado - nación. ${ }^{1}$ Sin embargo, una vez llegados a este punto, si se quería consolidar esta identidad nacional era necesario definir la idiosincrasia de la nueva nación emergente, los rasgos que definían el carácter y el temperamento de la raza española, en definitiva, se trataba de buscar símbolos identificadores. ${ }^{2}$ Uno de los caminos para conseguirlo fue volver la mirada hacia el pasado, y en la idea de que cuanto más antiguo fuese el origen de estos rasgos, mejor estaría definido el estado - nación que acababa de nacer, no tardó en convertirse la Antigüedad en el campo de búsqueda predilecto. La protohistoria peninsular fue el periodo que suscitó más entusiasmo, principalmente porque se tenía la opinión generalizada de que fue entonces cuando se empezaron a establecer las peculiaridades identitarias de la nación española. ${ }^{3}$ A ello contribuyó, sin duda alguna, la invasión de Napoleón (1808 - 1814), el nuevo Aníbal, el nuevo Escipión con el que España reescribía una página de una historia ya vivida, la de la destrucción de Sagunto y Numancia.

En esta empresa de proporcionar elementos de cohesión a la identidad colectiva del estado - nación España, dos disciplinas desempeñaron un papel crucial: la Historia y la Pintura. Mientras que el historiador buscaba en el pasado esas señas de identidad, esos acontecimientos que reflejaban la esencia de la nación; el pintor, cuya base documental eran los libros de historia, los popularizaba en sus cuadros. Con la ayuda de uno y de otro, el abnegado patriotismo español de los habitantes de Sagunto y Numancia, su espíritu de independencia y el exacerbado heroísmo que ambas ciudades mostraron en su lucha contra los dos grandes colosos del Mediterráneo (Cartago y Roma), se convirtieron rápidamente en símbolos de la nueva identidad nacional. Se trataba, en definitiva, de la lucha colectiva de «los primeros es-

1. Una breve síntesis sobre el proceso de nacimiento de España como estado - nación en J. Álvarez Junco, Mater dolorosa. La idea de España en el siglo XIX, Madrid, 2001, 155-171.

2. Son las «fronteras de inclusión» a las que se refiere Álvarez Junco, Mater..., op. cit., 190.

3. Prueba de ello es la importancia que los primeros pobladores de la península ibérica tienen en las Historias de España de este periodo, como en las de Modesto Lafuente o Antonio Cabanilles, porque, como bien afirma López-Vela, «en ellos se encuentra la idiosincrasia, la base esencial que luego se verá reflejada a lo largo de la historia nacional» (R. López-Vela, "De Numancia a Zaragoza. La construcción del pasado nacional en las Historias de España del ochocientos”, en: R. García Cárcel, La construcción de las Historias de España, Madrid, 2004, 209-210). La misma idea ya la encontramos en Álvarez Junco, Mater..., op. cit., 206. 
pañoles verdaderos» contra «conquistadores extraños y ajenos al ser nacional», ${ }^{4}$ una idea que encajaba perfectamente con el creciente patriotismo de los nuevos tiempos.

Numancia y Sagunto, junto con Viriato, formaban parte, en palabras de Pérez Vejo, de «la trilogía sagrada de la mitología de lo español», ${ }^{5}$ y muy tempranamente pasaron al imaginario colectivo del pensamiento liberal del XIX, como lo evidencia la oratoria política de estos años. En el ámbito de la vida parlamentaria española, las dos ciudades fueron dos exempla históricos a los que en ocasiones recurría el orador para dirigirse a un público cultivado y antagónico, al que trataba de convencer. ${ }^{6}$ En este proceso de persuasión, disminuir la distancia entre el emisor y el receptor era un paso muy importante, y que mejor manera para hacerlo que mencionar en el discurso dos gestas históricas que formaban parte una pasado compartido por todos. ${ }^{7}$

Nuestro objetivo en este artículo es analizar el papel que desempeñaron estos dos exempla históricos en el parlamentarismo español a lo largo de setenta años, desde el triunfo de la soberanía popular en la revolución de 1868 hasta el 2 febrero de 1939, momento en el que las Cortes republicanas celebraron en el castillo de Figueras su última reunión dentro del territorio español. ${ }^{8}$ Pero antes, referiremos los hechos que convirtieron a Sagunto y a Numancia, ya en la Antigüedad, en símbolos de la independencia y el heroísmo hispanos.

\section{El nacimiento del mito}

El protagonismo de Sagunto en una de las guerras más importantes que tuvo lugar en el Mediterráneo durante la Antigüedad, la Segunda Guerra Púnica (218 - 201 a. C.), reservó a esta ciudad un lugar en la Historia, y todo ello gracias a Polibio, Livio y Apiano, principalmente. Fue entonces cuando se formó la leyenda de esta ciudad, que fue sitiada en 218 a. C. por el general cartaginés Aníbal y que cayó tras ocho meses de duro asedio.

El desembarco de Amílcar Barca en las costas gaditanas en 237 a. C. y su posterior expansión por la franja costera meridional y el valle del Guadalquivir mostraban el interés

4. T. Pérez Vejo, España imaginada. Historia de la invención de una nación, Barcelona, 2015, 52/ 53.

5. T. Pérez Vejo, Pintura de historia e identidad nacional en España, Tesis Doctoral, Universidad Complutense de Madrid, 1996, 971.

6. Esa era la principal finalidad del exemplum, como ya establecieron dos grandes maestros de la palabra, Cicerón (Part. 14.49) y Quintiliano (Inst. 5.11.6).

7. Sobre el empleo y función del exemplum en el discurso, vid. Ch. Perelman - L. Olbrechts-Tyteca, Tratado de la Argumentación. La nueva Retórica, Madrid, 1989, 536-546; J. Alcolea. s. v. "Ejemplo", en: L. Vega Reñón - P. Olmos Gómez (Eds.), Compendio de lógica, argumentación y retórica, Madrid, 2011, 218 220 .

8. La derrota republicana supuso la desaparición de un sistema parlamentario que había estado vigente en la España liberal desde La Gloriosa, y que sólo fue interrumpido durante ochos años por el golpe militar de Miguel Primo de Rivera (1923 - 1931). Para una visión general del parlamentarismo a lo largo de este periodo, vid. M. Pérez Ledesma, "La vida parlamentaria en España: de la revolución de 1868 a la derrota republicana de 1939”, en: G. Capellán de Miguel (Ed.), Parlamento y parlamentarismo de la España Liberal. Manuel de Orovio y Práxedes Mateo-Sagasta, Logroño, 200o, 23-65. 
de Cartago por la península ibérica, un interés que con el tiempo desencadenó una rivalidad interna en la propia Sagunto. ${ }^{9}$ No tardaron en formarse dos facciones dentro de ciudad, los que preferían una mayor influencia de Cartago y los que, por el contrario, querían la de Roma. ${ }^{10}$ Era evidente que cuando el equilibrio de fuerzas se inclinase hacia uno u otro lado el conflicto sería inevitable. Así ocurrió, y para justificar el asedio a la ciudad, Aníbal, según nos relata Apiano, convenció a los turbuletas, vecinos y viejos enemigos de los saguntinos, ${ }^{11}$ para que se quejasen de que los saguntinos «les devastaban los campos y les infligían otros muchos ultrajes». ${ }^{12}$ Fue entonces cuando Aníbal, un hombre que según Polibio «estaba poseído de irreflexión y de coraje violento», que "no se servía de las causas verdaderas y se escapaba hacia pretextos absurdos», ${ }^{13}$ puso sitio a Sagunto.

El relato más detallado de los ocho meses de asedio nos lo proporciona Livio, quien refiere con detalle sus preparativos, como arrasaron los campos adyacentes a la ciudad; los sucesivos ataques a las murallas y la lucha cuerpo a cuerpo sobre los escombros de las mismas; $y$, por último, el uso de máquinas de guerra para destruir definitivamente las defensas de Sagunto y hacerse con el control del enclave y de su ciudadela. ${ }^{14}$

Durante el tiempo que duró el asedio, el ánimo de los saguntinos no decayó, se mantuvieron firmes y rechazaron al enemigo en sucesivas ocasiones, a pesar de superarles en número $;{ }^{15}$ incluso cuando se derrumbó un sector de la muralla, no dudaron en ponerse ellos mismos como barrera entre los asaltantes y la ciudad desprotegida, sin retroceder ni un paso. ${ }^{16} \mathrm{Y}$ al flaquear sus fuerzas, en lugar de aceptar las condiciones de rendición que les ofrecía Aníbal, «reunieron en el foro todo el oro y plata del tesoro público y privado, y arrojándolo al fuego encendido con ese fin deprisa y corriendo, también ellos en su mayor parte se precipitaron en las llamas». ${ }^{17}$ Finalmente, Aníbal atacó con todos sus efectivos bajo el lema de matar a todos los saguntinos en edad militar que, o se habían encerrado con sus familias en sus casas, que se desplomaban bajo las llamas, o se enfrentaban en un combate a muerte con los soldados de Aníbal. ${ }^{18}$

9. Plb. 3.15.6-7.

10. No es nuestro objetivo aquí entrar en esta cuestión, que está ampliamente tratada en A. J. Domínguez Monedero, "Sagunto, el emporion de Arse, punto de fricción entre las políticas de Roma y Cartago en la península ibérica”, CuPAUAM, 37-38, 2011-2012, 395-417.

11. Liv. 21.6.1. No se trata de los turdetanos, como asegura Livio, sino de los turbuletas, vid. J. Uroz Sáez, “¿Turbuletas o turdetanos, en la guerra de Sagunto?”, Lucentum, 1, 1982, 179-181.

12. App. $I b$. 10. Polibio, por su parte, dice que Aníbal envió correos a Cartago con el fin de saber qué debía hacer, ya que los saguntinos estaban atacando a los pueblos vecinos sometidos a los cartagineses (Plb.3.15.8).

13. Plb. 3.15.9.

14. Liv. 21.7.4-21.9.2/ 21.11.3-15.1.

15. Liv. 21.9.1-2.

16. Liv. 21.8.8.

17. Liv. 21.14.1.

18. Liv. 21.14.3-4. 
El heroísmo que mostraron los saguntinos en los últimos días del asedio ya lo había relatado, antes que Livio, Diodoro Sículo, quien puntualiza que los saguntinos fundieron los objetos de oro y plata con plomo y cobre para que no fuesen útiles a Aníbal, y añade, además, que después se lanzaron heroicamente a una lucha en la que murieron todos, y que las mujeres degollaron a sus hijos para después ahorcarse. ${ }^{19}$

La escena no podía ser más dramática, de manera que Sagunto no tardó mucho en convertirse en el paradigma de un pueblo que elegía una muerte honrosa antes que la rendición, y así se ve ya en el s. I d.C. en Quintiliano ${ }^{20} \mathrm{y}$ Lucano. En el caso del segundo, la imagen de los niños arrebatados de los pechos de sus madres para ser arrojados al fuego, la de las esposas pidiendo la muerte a sus maridos o la de los hermanos matándose entre ellos, encajaba perfectamente con su épica histórica y con la imagen del heroísmo saguntino. ${ }^{21}$ Tampoco falta el topos de la ingesta de carne humana por parte de los sitiados, ${ }^{22}$ ni intentos de justificar el parricidio que cometieron los saguntinos. ${ }^{23}$

Pero Sagunto fue también un arquetipo de fidelidad hacia Roma por encima de cualquier adversidad. ${ }^{24}$ Para Valerio Máximo es esta fidelidad a Roma la que les lleva a hacer una hoguera pública en la plaza y arrojar a ellas sus más queridas pertenencias y a sí mismos. ${ }^{25}$ Sin embargo, a pesar de que la imagen de Sagunto como icono de fidelidad domina en la historiografía romana, esta no trascendió a la posteridad. En realidad, fue una creación de la historiografía latina para justificar y legitimar la declaración de guerra a Cartago por parte de Roma, sobre la base de una antigua alianza de la segunda con Sagunto. ${ }^{26}$ Esta virtud de Sagunto pronto se olvidó y bien pudo ser san Agustín quien más contribuyó a ello, pues para él Sagunto fue destruida por «haber permanecido demasiado fiel» a la impía Roma y a sus dioses, unos dioses que permitieron que los saguntinos padeciesen tantas penurias que solo vieron liberación en la muerte. ${ }^{27}$ No era esta una imagen que interesaba transmitir a la posteridad.

Con todo, entre los escritores grecolatinos fue la ciudad arévaca de Numancia, y no la edetana Sagunto, el símbolo por excelencia del heroísmo y la independencia de todo un pueblo.

Cuando el Senado romano tuvo conocimiento de que los de Segeda (Mara - Belmonte de Gracián), habían decidido ampliar su recinto amurallado con el fin de acoger a gentes de las ciudades vecinas, envió una embajada para comunicarles que no debían continuar con los trabajos porque estaban incumpliendo los acuerdos establecidos con Tiberio Sempronio

19. Diod. 25.15; cfr. App. Ib. 12.

20. Quint. Inst. 3.8.23.

21. Luc. 3.350 .

22. Petr. Sat. 141.9.

23. Sen. Cont. 9.4.5.

24. Sall. H. 2.64.1; Mel. 2.91-94; Plin. NH 3.20; Flor. 1.22; Amm. 15.10.10.

25. V. Max. 6.6. (ext.)1.

26. Sobre esta antigua vinculación entre Sagunto y Roma en las fuentes clásicas, vid. Domínguez Monedero, “Sagunto..., op. cit., 400-402/ 408-412.

27. August. Civ. Dei 3.20. 
Graco en 179 a. C. ${ }^{28}$ Sin embargo, para los segedanos no era así, ya que Graco había prohibido construir nuevas ciudades, no fortificar las existentes o ampliar su recinto amurallado. ${ }^{29} \mathrm{Tal}$ contestación fue vista como una provocación y en 153 a. C. Roma envía al cónsul Q. Fulvio Nobilior a zanjar el asunto. Es en este momento cuando entra en escena la ciudad de $\mathrm{Nu}$ mancia, porque fue allí, al corazón del territorio arévaco, a donde se dirigieron las gentes de Segeda cuando en el verano de 153 a. C. Nobilior se presentó ante la ciudad con un ejército de 30.000 hombres. ${ }^{30}$ Fue entonces cuando comenzaron los sucesivos asedios del enclave que no tardó en convertirse en el centro de la resistencia celtibérica al dominio de Roma, ${ }^{31}$ tal y como lo atestiguan los escritores grecolatinos, los verdaderos artífices de la leyenda.

Para los historiadores clásicos la guerra que terminó con la destrucción de Numancia fue una guerra larga que inició Roma sin un motivo aparente. Lo único que había hecho la ciudad arévaca fue prestar ayuda a sus aliados los belos, y tal comportamiento era digno de alabanza, no de una guerra con «la nación que disponía de todas las fuerzas del universo», ${ }^{32}$ una guerra a la que Cicerón bautizó como «guerra de exterminio», y de la que Veleyo Patérculo dijo que fue «más penosa» que la de Viriato. ${ }^{33}$ Pero a pesar de ser una guerra desigual, no faltaron momentos de gloria para los numantinos, como las sucesivas derrotas que infringieron a Nobilior ${ }^{34}$ o a Pompeyo Aulo, ${ }^{35}$ o el acuerdo tan favorable que firmaron con Manciano. ${ }^{36}$ Estas sucesivas deshonras romanas sirvieron para presentar a la ciudad arévaca como el «terror de la República», ${ }^{37}$ que llevó a Roma a «estremecerse con el terror de la guerra de Numancia», ${ }^{38}$ y a algunos autores a compararla con la amenaza que supuso Cartago en su momento. ${ }^{39} \mathrm{Y}$ así nació la fama de su ferocidad e invencibilidad que encontramos en la historiografía romana desde el s. I a.C., ${ }^{40}$ y que se destacó aún más cuando algunos autores clásicos afirmaron, erróneamente, que la ciudad carecía de murallas. ${ }^{41}$

28. Diod. 31.39; App. Ib. 44.

29. Id.

30. App. Ib. 45.

31. Después de Q. Fulvio Nobilior (153 - 152 a. C.) los asedios a Numancia estuvieron protagonizados por M. Claudio Marcelo (152 - 151 a. C.), Q. Pompeyo Aulo (141 - 139 a. C.), Popilio Lenas (138 a. C.), Hostilio Manciano (137 a. C.) y Publio Cornelio Escipión Emiliano (134 - 133 a. C.), el vencedor de Numancia. Para un relato detallado de la Guerra Numantina, vid. A. Jimeno Martínez - J. I. de la Torre Echávarri, Numancia, símbolo e historia, Madrid, 2005, 11-24.

32. Flor. 2.18.

33. Cic. Off. 1.11; Vell. 2.1.3-4.

34. App. Ib. 46.

35. App. Ib. 78.

36. App. Ib. 80.

37. Cic. Mur. 58.

38. Vell. 2.90.3. Sobre este miedo a Numancia, vid. Flor. 2.18; Plb. 35.4.4.

39. Cic. Agr. 2.90/ Cat. 4.21; Flor. 2.18; App. Ib. 98

40. Flor. 2.18; Aur. Vict. de vir. ill. 49.

41. Sobre esta cuestión, vid. Jimeno Martínez - Torre Echávarri, Numancia..., op. cit., 30. 
Pero todavía quedaba el momento más trágico de toda la contienda, el final de una ciudad que, tras quince meses de asedio y hostigada por el hambre, decidió morir antes que rendirse a Escipión y a Roma. Al igual que los saguntinos, los numantinos prefirieron una honrosa muerte a una rendición incondicional que les iba a suponer entregar las armas, la ciudad y perder su libertad. ${ }^{42}$

El sacrificio colectivo que convirtió a Numancia en inmortal fue alabado, entre otros, por Séneca, que habla de la grandeza de Escipión, pero también de la del «heroico espíritu de los sitiados, que se sabe que no está cercado quien tiene el escape de la muerte y lanza el último suspiro en brazos de la libertad $»{ }^{43}$ por Floro, para quien el valor de los numantinos es equiparable con el de los habitantes de Cartago, y así se explica que Roma pusiese al frente de la guerra numantina a quien había destruido Cartago, Publio Cornelio Escipión Emiliano; no olvida tampoco pintar un dramático y heroico final en el que los habitantes de Numancia «se destruyen a sí mismos, a los suyos y su patria, con la ayuda de la espada, del veneno y del fuego que se había extendido por todas partes». ${ }^{44}$ Por el contrario, Apiano relata el «espectáculo terrible y prodigioso» que fue ver aparecer a los supervivientes ante el enemigo, «sucios, llenos de porquería, con las uñas crecidas, cubiertos de vello y despedían un olor fétido», y eso les hacía «dignos de compasión, pero temibles en su mirada, pues aún mostraban en sus rostros la cólera, el dolor, la fatiga y la conciencia de haberse devorado los unos a los otros». ${ }^{45}$

Todavía más dramático es el final que nos cuenta Valerio Máximo, en el que Retógenes incendia primero su barrio y después coloca una espada desenvainada en el centro de la plaza; entonces ordena que luchen de dos en dos, arrojando al vencedor a las llamas con la cabeza cortada; y cuando ya habían muerto todos él también se arroja a las llamas. ${ }^{46}$

Curiosamente, muy pocos relatan al detalle de que, impulsados por el hambre y la necesidad de prolongar su resistencia a Roma, «comieron carne humana cocida, en primer lugar la de aquellos que habían muerto y posteriormente los más fuertes causaron violencia a los más débiles». ${ }^{47}$ Este comportamiento, que venía muy bien para justificar y ensalzar el papel civilizador de Roma, es duramente criticado por Veleyo Patérculo, para quien «no puede servirles como excusa la necesidad, pues los que al final habían de morir, no tenían necesidad de vivir de tal manera»; ${ }^{48}$ pero para otros, como Apiano, fue fruto de las circunstancias extremas que padecían, que les hicieron «volverse salvajes de espíritu»y «semejantes a las fieras». ${ }^{49}$

La resistencia de Numancia a Roma y su trágico final, símbolos ambos de su valor y amor por la libertad, no solo contribuyeron a hacer de esta ciudad una leyenda, sino que jus-

\footnotetext{
42. App. Ib. 95

43. Sen. Ad Pol. Con. 1.

44. Flor. 2.18.

45. App. Ib. 97.

46. V. Max. 3.2.(ext)7.

47. App. Ib. 96.

48. Vell. 7.6.

49. App. Ib. 96.
} 
tificaban la presencia de un general de la talla de Publio Cornelio Escipión Emiliano, el héroe que había vengado las afrentas de la ciudad arévaca. ${ }^{50}$

Construida la leyenda, solo quedaba su transmisión y es aquí donde la Historia contra los paganos de Orosio jugará un importante papel. En su relato de los acontecimientos son continuas las alusiones al valor de los numantinos, de los que los romanos deben aprender a ser «justos, fieles y misericordiosos». ${ }^{51} \mathrm{El}$ coraje de este pueblo queda todavía más patente cuando el discípulo de san Agustín afirma que con cuatro mil soldados contuvieron durante catorce años a cuarenta mil romanos, a los que vencieron en numerosas ocasiones y obligaron a aceptar alianzas vergonzosas $;{ }^{52} \mathrm{o}$ al afirmar que cuando se retiraban de la lucha para regresar a la ciudad lo hacían en orden, porque no se trataba de una huida. ${ }^{53}$ Tampoco Orosio deja supervivientes y para ello escoge el final de una Numancia en llamas donde perecieron todos sus habitantes, de esa manera los romanos no se vieron como vencedores, porque fueron los numantinos quienes, voluntariamente, escaparon al destino que Roma les había reservado. ${ }^{54}$

\section{Sagunto y Numancia en el Congreso los diputados}

En el periodo que abarca nuestro estudio (1868 - 1939), estas dos ciudades son mencionadas como exempla históricos en cuarenta y un discursos, que se distribuyen de la siguiente manera: dieciséis durante el Sexenio Revolucionario (septiembre 1868 - diciembre 1874), veinte durante la Restauración Borbónica (enero 1875 - mayo 1902), tan solo cuatro bajo el reinado de Alfonso XIII (mayo 1902 - abril 1931) y uno bajo la Segunda República (1931 - 1939). Porcentualmente, el periodo más rico en estos exempla es el Sexenio Revolucionario, seguido por el reinado de Alfonso XII (1875 - 1885) y la regencia de María Cristina de HabsburgoLorena $(1885$ - 1902). Su presencia durante el reinado de Alfonso XIII y en la Segunda República es anecdótica.

De todo este conjunto, en veinticuatro ocasiones son nombradas ambas ciudades, en diez solo Numancia y en siete solo Sagunto. En el primer caso se sigue, por regla general, el orden cronológico de los acontecimientos y la finalidad es hacer hincapié en el abnegado patriotismo y amor por la libertad de sus gentes, al igual que cuando solo es mencionada Numancia. Sin embargo, cuando solo se hace referencia a Sagunto, o bien es en relación con la frase hecha «mientras se consultaba a Roma, Sagunto ardía», que se utiliza para poner en

50. Vell. 2.4.2-3. Sobre la presencia de Escipión como "héroe civilizador", vid. Jimeno Martínez - Torre Echávarri, Numancia..., op. cit., 36-37.

51. Oros. 5.5.1.

52. Oros. 5.7.3.

53. Oros. 5.7.15.

54. Oros. 5.7.17. En su relato, no hay mención alguna al canibalismo. 
evidencia la dilación en la toma o puesta en práctica de decisiones: ${ }^{55} \mathrm{o}$ bien, la mención a esta ciudad es necesaria por tratarse de propuestas que afectan a su región. ${ }^{56}$

En cualquier caso, las alusiones a Sagunto, a Numancia o a ambas ciudades animaron los debates que se suscitaron en el Congreso de los Diputados a lo largo de estos setenta años, unos debates en los que se discutieron asuntos de la más variada índole. Durante el Sexenio Revolucionario se recurrió a ellos para adornar las intervenciones en torno al proyecto de ley de supresión de las garantías constitucionales y autorización de declarar en estado de guerra aquella parte del territorio que se estimase conveniente; las deliberaciones sobre la concesión de indemnizaciones a ciudades que sufrieron grandes pérdidas con las guerras, como Barcelona en su resistencia a los Borbones, o Estella en la Tercera Guerra Carlista; los debates sobre la ley de reemplazos; la política reformista de ultramar; y, por último, las apasionadas intervenciones que tuvieron lugar tras la elección de un rey extranjero y, meses más tarde, después del tradicional discurso de la corona que el nuevo rey dirigió a las Cortes el 3 de abril de 1871.

Con la Restauración, periodo en el que se sitúa el segundo gran bloque de exempla, Sagunto y Numancia animaron, entre otros, los debates sobre la libertad de cultos, la cuestión foral, la corrupción electoral, algunos asuntos del ejército, como cuestiones presupuestarios, la constitución del Estado Mayor, su Ley Constitutiva o el servicio militar obligatorio; y también algunos debates sobre la política general de Ultramar. Con Alfonso XIII, Sagunto y Numancia tan solo aparecen en un par de debates en torno al ejército, como la necesidad de reorganizarlo y de renovar y modernizar su armamento; y también son mencionadas en las acaloradas discusiones sobre la autonomía y nacionalismo catalán.

55. El diputado por Oviedo, Antonio Sánchez Campomanes, que se oponía al asociacionismo dentro de las filas del ejército español por considerarlo el primer paso hacia la dictadura, y no entendía la demora en tomar una resolución que para él era muy clara, dijo a los presentes, «si persistís en vuestra conducta de Cónsules y de Pretores, destruiréis á Sagunto» (DSC, t. 19, nº 82, 4-5-1887, p. 2222). Años más tarde, en 1922, Santiago Alba Bonifaz, diputado de la Izquierda Liberal por Granada, utiliza la misma frase hecha para recriminar al gobierno anterior que no habían hecho nada durante los seis meses que gobernaron, por eso les dice que «mientras los cónsules deliberaban, Sagunto se perdía» (DSC, t. 31, n 46, 26-5-1922, p. 1847). Con esta misma expresión Eugenio Vázquez Gundín, diputado de Acción Popular por La Coruña, interrumpe el discurso del diputado por Oviedo Eduardo Piñán y Malvar, cuando este afirma que la comisión de la que forma parte también «siente simpatía por esa clase humilde», prueba de ello es la proposición de ley sobre la pesca litoral que él mismo presentó hace más de un año, pero sobre la que todavía no se había emitido ningún dictamen (DSC, t. 32, nº 262, 15-11-1935, p. 10660).

56. José Manteca y Oria, diputado por Valencia, para justificar la necesidad de añadir una carretera de tercer orden para mejorar las comunicaciones entre Utiel a Chelva, esgrime como argumento que en esta región están las mismas sendas y trochas que cuando «una parte de los ejércitos de Aníbal se dirigían por aquel país al sitio y destrucción de la heroica Sagunto» (DSC, t. 19, n 91, 12-4-1888, p. 2402). Juan Navarro Reverter, diputado por el distrito electoral Segorbe-Vivier (Castellón), se refiere a Sagunto cuando propone que en la condonación de pago de contribuciones a la provincia de Almería se añada también los partidos judiciales de Segorbe y Viver (Castellón), porque, al igual que Almería, «la región valenciana de Castellón de la Plana, Jericá la celtíbera, Viver de las aguas, Segorbe la heroica, Sagunto la inmortal (...)», también se han visto afectados por las inundaciones (DSC, t. 19, no 85, 3-4-1889, p. 2278). 
No es nuestra intención aquí centrarnos en todos estos debates, ya que en la mayoría de ellos el mensaje que se quiere transmitir con la utilización de estos dos exempla es muy similar. Por lo tanto, hemos optado por hacer una selección de aquellos que a nuestro juicio nos han parecido los más representativos y los hemos agrupado en cinco bloques temáticos:

- Un rey extranjero: Amadeo I de Saboya (1871 - 1873).

- Un nuevo ejército para España.

- Las colonias de Ultramar.

- La libertad de culto.

- Las Saguntos y Numancias del s. XIX: Barcelona, Estella y Bilbao.

\section{Un rey extranjero: Amadeo I de Saboya (1871 - 1873)}

La revolución de 1868 supuso el final del reinado de Isabel II y la formación de un gobierno provisional que, bajo la presidencia de Francisco Serrano y Domínguez, estableció el sufragio universal masculino y convocó elecciones a Cortes Constituyentes para mediados de enero del siguiente año. A partir de este momento las Cortes (poder legislativo) representarían la soberanía nacional y estarían por encima del poder ejecutivo. Esta novedad se materializó en la Constitución de 1869, que también estableció como forma de gobierno la monarquía constitucional. La consecuencia inmediata fue buscar un rey, pero un rey que encajase con la idiosincrasia y la nueva situación del país, es decir, un rey democrático, liberal y católico, que, además, sancionase lo que decidiese la mayoría parlamentaria.

El 16 de noviembre de 1870 las Cortes Constituyentes eligieron rey de España a Amadeo de Saboya, hijo del rey de Italia Víctor Manuel, por un total de 191 votos de los 352 diputados que tomaron parte en la votación. El nuevo rey fue presentado como el rey elegido por el pueblo, pero para republicanos y carlistas era el rey de Prim, es decir, el rey de los radicales y de los revolucionarios; también fue rechazado por la aristocracia borbónica y por el pueblo. ${ }^{57}$ De manera que antes de llegar a España, el nuevo monarca ya tenía a casi todos en su contra, y eso auguraba para el italiano un complicado y breve reinado. Y así ocurrió, Amadeo llegó a Madrid el 2 de enero de 1871, tras el asesinato de uno de su más fuertes apoyos, el general Prim, y la noche del 10 de febrero de 1873, tras renunciar a la corona, Amadeo y su esposa María Victoria tomaron un tren hacia Portugal. ${ }^{58}$

Sin embargo, consiguió algo inimaginable para aquellos años, unir a la oposición. Una prueba de ello son los discursos que fueron pronunciados en las Cortes por diputados republicanos y carlistas. Y este es el punto al que queremos llegar, pues en todos ellos se alude a Numancia y Sagunto como símbolo de la independencia de España.

57. En relación con esta oposición, vid. C. González Cuevas, Historia de la derecha española. De la Ilustración a nuestros días, Madrid, 2000, 137-138 y C. Bolaños Mejía, El reinado de Amadeo de Saboya y la monarquía constitucional, Madrid, 2014, 169-186, espec. 169-171/ 183/ 185-186.

58. Una síntesis de su reinado en J. Fontana, La época del liberalismo, Madrid, 2007, 366-371. 
El líder republicano Emilio Castelar y Ripoll, diputado por Lérida, unos días antes de que se votase la elección de un rey para España, recrimina a Juan Prim y Prats, Presidente del Congreso, que hubiese ofrecido la corona de España a varios candidatos extranjeros, sin la debida autorización parlamentaria; unos candidatos que el pueblo español no conocía y que, por lo tanto, iban a ser incapaces de representar su soberanía. ${ }^{59}$ También le culpa de querer traer a un rey extranjero, y no comprendía cómo alguien se había atrevido a hacerlo, ni cómo este rey se atrevía a venir a España, a un país cuyos habitantes habían luchado trescientos años contra los romanos y setecientos contra los árabes. ${ }^{60}$ Estas guerras convirtieron al pueblo español en un fanático de su independencia, y esto se podía ver en cualquiera de las provincias españolas, como en Valencia por Sagunto. ${ }^{61}$

El 20 de abril de 1871, en un nuevo discurso en torno al mismo tema, insiste Castelar en que la nación española está celosa de su independencia y de su libertad, una nación, dice, que ha visto con horror como fue sustituido el nombre de Sagunto por un nombre extranjero. ${ }^{62}$ En su intervención insiste nuevamente en los años de dominación romana y árabe. ${ }^{63}$

En el mismo sentido son mencionadas Sagunto y Numancia en los discursos que se pronunciaron en torno al voto particular de Cándido Nocedal Rodríguez de la Flor, diputado por Vizcaya y líder del partido carlista. Nocedal quería demostrar al nuevo monarca la ilegalidad de su situación y para ello, al igual que antes hizo Castelar, elogia el espíritu independentista de los españoles al afirmar que es

«vana empresa la de tratar de imponer cosa ninguna a esta nación que registra en su historia nombres como Sagunto y Numancia, y en sus recientes anales glorias como las de Bailén, Gerona y Zaragoza. El pueblo que perseveró denodado en rechazar toda extraña dominación, desde la cartaginesa, en remotos siglos, hasta la francesa en el presente, tiene ejecutoriada su independencia». ${ }^{64}$

Los días 25 y 31 de mayo y 1 y 2 de junio se debatió en el Congreso el voto de Nocedal. En este debate, en el que hubo discursos a favor y en contra, solo intervinieron los liberales (los gubernamentales) y los carlistas, los republicanos y la minoría alfonsina se mantuvieron

59. DSC, t. 14, n 315, 3-11-1870, p. 9117. Una relación de estos candidatos en M. Rolandi Sánchez-Solis, "Aportación a la historia del republicanismo y el federalismo español del siglo XIX. I. Desde sus orígenes hasta el final del reinado de Isabel II", Cuadernos Republicanos, 58, 2005, 33-34.

60. DSC, t. 14, no 315, 3-11-1870, p. 9125.

61. Id.

62. DSC, t. 15, n 12, 20-4-1871, p. 215. El nombre de Sagunto fue sustituido por Morbyter, que más tarde sería Murviedro en castellano y Murvedre en valenciano, y así permaneció hasta que el gobierno provisional de 1868 restituyó a esta ciudad su antiguo nombre romano.

63. DSC, t. ,15, no 12, 20-4-1971, p. 215. En esta legislatura (1870 - 1871) Castelar era diputado por Huelva.

64. DSC, t. 15, Apéndice segundo al no 44, p. 1. Como neocatólico era fiel súbdito de la monarquía de Isabel II (González Cuevas, Historia de la derecha..., op. cit., 127). 
al margen.$^{65}$ En contra de Nocedal estaba Francisco Romero Robledo, miembro de la comisión de contestación al discurso de la Corona y diputado del Partido Constitucional de Sagasta por Málaga. Este diputado no entendía, y así lo expresaba en su discurso, qué tenía que ver Zaragoza, Gerona, Sagunto y Numancia con la situación actual; y solicitaba que Nocedal explicase por qué en su voto «se habla y se hace alarde jactancioso del carácter independiente é indomable de nuestro país». ${ }^{66}$ Para el diputado de Málaga, el nuevo rey no había sido impuesto, ningún ejército extranjero había pisado suelo español y nadie pretendía dominar el país por la fuerza. ${ }^{67}$ En definitiva, Amadeo I de Saboya era un monarca libremente elegido por la voluntad soberana del pueblo español, por lo tanto, estaba de más hacer alarde del indomable carácter español. ${ }^{68}$ Finalmente, el 2 de junio interviene Nocedal para defender su voto particular, y en relación con su mención a Sagunto, Numancia, Gerona y Zaragoza, deja muy claro que en cualquier otro momento toda la Asamblea habría aplaudido y se habría adherido al diputado que hubiese «cantado las glorias de la Patria». ${ }^{69}$

\section{Un nuevo ejército para España}

La Guerra de la Independencia (1808 - 1814) constató la necesidad de reformar el ejército, y ya en las Cortes de Cádiz se empezó a discutir sobre la transformación del Ejército Real del Antiguo Régimen en un Ejército Nacional, que se creó en 1846, durante la Década Moderada.

Sin embargo, todavía había que decidir cómo sostener un ejército permanente, cómo organizarlo y cómo llevar a cabo los reemplazos. Esta última cuestión fue una de las más discutidas por los parlamentarios españoles. ${ }^{70}$ En el marco de estos debates, el heroísmo de los habitantes de Sagunto y Numancia, o lo que es lo mismo, el de los españoles, compensará para unos el no contar con un ejército numeroso y bien pertrechado; mientras que para otros de bien poco servirá el valor si no hay recursos.

65. Un resumen de los debates en torno a este voto particular en B. Urigüen, Orígenes y evolución de la derecha española: el neo-catolicismo, Madrid, 1986, 400-424.

66. DSC, t. 15, no 51, 2-6-1871, p. 1372.

67. Id.

68. Id.

69. DSC, t. 15, no 51, 2-6-1871, p. 1376. El voto de Nocedal fue rechazado, pero cuestionó la presencia en España de la nueva dinastía y mostró muy claramente que se sustentaba sobre bases muy poco sólidas (Urigüen, Orígenes..., op. cit., 414).

70. La prestación del servicio militar había sido vista siempre como una contribución directa que podía eludirse mediante el pago de una cuota en dinero, o por motivos de salud. De esta forma estaban exentos los que tenían dinero para pagar su redención, o los que estaban muy bien relacionados con el poder municipal o con instancias estatales superiores. Tal circunstancia explica que una de las demandas habituales de los movimientos populares, y también una de las promesas electorales de los partidos políticos no conservadores, fuese la eliminación del sistema de quintas. En relación con este sistema de reclutamiento, vid. A. M. Fernández Muñiz, "Las quintas. Sistema de reclutamiento: explotación para unos y negocio para otros (1868-98)", Estudios de Historia Social, 44, 1988, 553-559. 
Poner fin al servicio militar obligatorio y crear un ejército de voluntarios retribuidos era el deseo de la comisión que debía informar el Proyecto de Ley sobre reemplazo y organización del ejército, cuyo debate se inició el 10 de marzo de 1870, pero el sistema de quintas no podía ser abolido, porque el Tesoro no disponía de fondos suficientes para costear un ejército de voluntarios retribuidos. ${ }^{71}$ En este ambiente comenzó a discutirse el mencionado proyecto de ley. En uno de los días de debate, Buenaventura Abarzuza Ferrer, diputado republicano por Alicante, reprochaba a la cámara el acuerdo generalizado respecto a los reemplazos, porque para él, que creía en el espíritu del pueblo, serían necesarios tan solo «en caso de invasión extranjera, y de tener que defender la integridad del territorio y la nacionalidad». ${ }^{72}$ El discurso de Abarzuza fue contestado por el diputado del partido Demócrata-Radical por Granada, Ángel José Luis Carvajal y Fernández de Córdoba (Marqués de Sardoal), quien le aclaró que un ejército no se improvisaba y que la suma de patriotismo de que era capaz el pueblo español no sería suficiente para resistir victoriosamente a un ejército ${ }^{73}$. Para ello solo tenía que comparar los resultados de las batallas libradas por «las masas populares» con las que habían protagonizado las fuerzas regulares: el entusiasmo y el heroísmo de las primeras no evitaron cerrar el paso al francés en Zaragoza y Gerona, las Numancia y Sagunto del siglo XIX. ${ }^{74}$ El debate continúa en los días siguientes, esta vez Emilio Castelar y Ripoll propone que la excepción de quintas de la que gozaba Vascongadas se extendiese a todas las provincias españolas a partir de $1871 .{ }^{75}$ Para este diputado, a cuyo círculo pertenecía Abarzuza, una democracia no necesita mucha fuerza militar, porque donde había mucho ejército no había libertad. ${ }^{76}$ Es partidario de un ejército de ciudadanos «que en tiempos de paz se está tranquilo en su casa, en reserva, porque no tiene nada, absolutamente nada que hacer», pero que «cuando la patria peligra y corre graves riesgos de perder su independencia, en esas circunstancias supremas, (...) en esos momentos el ejército se levanta y acude afanosamente á conjurar el peligro, es decir, á salvar la honra y la independencia de la Pátria». ${ }^{77} \mathrm{Y}$ mientras que para el Marqués de Sardoal el heroísmo de Zaragoza y Gerona no impidió la entrada del ejército francés en esas ciudades, para Castelar, Napoleón perdió porque en España había algo más que un ejército, había un pueblo, «un ejército nacional que defendía la libertad y la independencia de un gran pueblo». ${ }^{78}$ Pone como ejemplo el sitio de Zaragoza, el gran día «en que un pueblo entero se sacrifica como la antigua Numancia y la antigua Sagunto». ${ }^{79} \mathrm{Y}$ si bien es verdad que en Zaragoza todo se improvisó, y que el francés entró, más cierto es que «de las grandes naciones que

71. DSC, t. 14, apéndice 3 al no 229, 3-3-1870, p. 1.

72. DSC, t. $14, \mathrm{n}^{\circ} 240,16-3-1870$, p. 6529.

73. DSC, t. 14 , no $240,16-3-1870$, p. 6531.

74. Id.

75. DSC, t. $14, \mathrm{n}^{\circ} 246,23-3-1870$, p. 6766.

76. Cita como ejemplos Suiza e Inglaterra, vid. DSC, t. 14, n 246, 23-3-1870, p. 6767-6768.

77. DSC, t. 14 , no $246,23-3-1870$, p. 6769.

78. DSC, t. 14 , no $246,23-3-1870$, p. 6771.

79. Id. 
pelean por la libertad y la independencia es posible conquistar el cadáver, pero no es posible conquistar el alma». ${ }^{80}$

Estas heroicas ciudades fueron también mencionadas en el debate que tuvo lugar el 29 de marzo de 1883 sobre la configuración del Estado Mayor, entre los militares Enrique de Orozco y de la Puente, diputado por Barcelona, y Carlos Espinosa de los Monteros Sagaseta de Ilurdoz, diputado por Castellón. A lo largo de este debate, el primero recrimina al segundo que cite organizaciones extranjeras en un país «en cuya historia hay páginas como las de $\mathrm{Nu}$ mancia y Sagunto, como las de Zaragoza y Gerona, como las de una epopeya de ocho siglos para conseguir su independencia y libertad». ${ }^{81}$ Sin embargo, para Espinosa de los Monteros, que también está muy conforme con el proyecto del gobierno, no cree que sea ninguna deshonra para España imitar lo que han hecho otros países, como Alemania, aunque el nuestro registre las glorias de Sagunto y Numancia, ejemplos que para el diputado están de más, porque «¿qué tiene que ver lo que pasó en tiempos de Aníbal en España, con lo que ocurre hoy en Alemania, en Inglaterra y en las demás Naciones?». ${ }^{82}$

Años más tarde, en 1888, bajo la regencia de María Cristina de Habsburgo-Lorena (1885 - 1902), Numancia y Sagunto se convierten en protagonistas de los debates sobre el proyecto de la Ley Constitutiva del Ejército presentado a Cortes por el General Manuel Cassola, ministro de la Guerra. En esta ocasión es Antonio Cánovas del Castillo, diputado por Murcia en esta legislatura, quien en pleno debate parlamentario utiliza a Sagunto y Numancia para convencer a su auditorio de que la inferioridad numérica que caracterizaba al ejército español, en comparación con el de otros países de Europa, no era ningún obstáculo para hacerse con la victoria. La clave para constituir un buen ejército no sería, según este diputado, el número de soldados, sino «su temperamento», «sus mayores aptitudes», «su sistema de guerra» e incluso «su táctica». ${ }^{83}$ En el caso español, continua Cánovas, destaca

«(...) la aptitud de defender fortalezas; aptitud que no se ha desmentido nunca, aptitud que se probó en los tiempos antiguos en Numancia y en Sagunto, aptitud que se probó en la guerra de la Independencia en Zaragoza, Gerona y otros cien puntos; aptitud que se ha demostrado en la guerra civil todos los días, hasta en los pueblos pequeños, con un puñado de nacionales encerrados en los campanarios; aptitud que no se ha desmentido en nuestra raza, y que yo espero no se desmentirá jamás». ${ }^{84}$

Sin embargo, aunque estas palabras pudieron levantar el ánimo de los presentes, de todos era conocido que la Hacienda española no podía sostener un ejército numeroso y bien equipado, como el que tenían otros países europeos. El aumento global de los gastos de la administración civil, las obligaciones presupuestarias en educación o en obras públicas, habían

80. Id. 6771.

81. DSC, t. $17, \mathrm{n}^{\circ} 74,29-3-1883$, p. 1661.

82. DSC, t. $17, \mathrm{n}^{\circ} 74,29-3-1883$, p. 1663.

83. DSC, t. $19, \mathrm{n}^{\circ} 66,8-3-1888$, p. 1694.

84. DSC, t. 19 , no 66, 8-3-1888, p. 1695. 
supuesto una drástica reducción en los gastos de defensa, que experimentarían pequeños incrementos tan solo durante conflictos bélicos puntuales. ${ }^{85}$

Con todo, recordar gestas épicas como las de Sagunto y Numancia o el heroísmo demostrado por los mártires de la patria, no podía reemplazar nunca a un ejército obsoleto, con pocos soldados y que necesitaba ser reorganizado y modernizado. Este planteamiento lo encontramos en el discurso del diputado conservador Francisco Silvela, ${ }^{86}$ y en los últimos debates sobre temas militares, en los que las palabras de Gervasio de Artiñano y Galdacano, diputado por Álava, no pueden ser más elocuentes: el objetivo de los soldados es «vencer con gloria» $\mathrm{y}$ «no el de sucumbir con heroísmo». ${ }^{87}$

\section{Las colonias de Ultramar}

El heroísmo de los habitantes de Sagunto y Numancia también se menciona en algunos de los discursos que se pronunciaron en los debates en torno a la situación de las colonias de Ultramar (Cuba y Puerto Rico).

Dos semanas después de que triunfase la revolución de 1868, estalla en Cuba una guerra colonial (10 de octubre de 1868). Fue una guerra de independencia que duró diez años y que iba a ser un gran obstáculo para la consolidación del régimen constitucional español. ${ }^{88}$ En este contexto, el gobierno de Madrid decidió emprender una política de reformismo colonial, que fue estimulada por la proximidad entre algunos políticos españoles y el grupo reformista criollo; ${ }^{89}$ y también por los librecambistas, quienes, agrupados en torno a la organización más representativa del movimiento librecambista, la Asociación para la Reforma de los Aranceles de Aduanas, se oponían a la esclavitud y al proteccionismo estatal en el comercio colonial. Por otra parte, la marcha de Isabel II y su posterior abdicación habían supuesto para España el establecimiento de derechos y libertades de los que no disfrutaban sus colonias, de manera que era necesario proyectar un programa de reformas sociales, políticas y administrativas. ${ }^{90}$

85. Una tabla de los gastos militares y su porcentaje en relación con los gastos generales del Estado desde 1820 hasta 1928 se puede ver en J. del Moral Ruiz - J. Pro Ruiz - F. Suárez Bilbao, Estado y territorio en España, Madrid, 2007, 518-521.

86. Ese es el planteamiento del discurso del diputado conservador Francisco Silvela, vid. DSC, t. 26, n 39, 7-1-1901, p. 1119-1120.

87. Artiñano critica aquí unas medidas sobre reorganización del ejército que se limitan al territorio peninsular, y que dejan a las islas abandonadas a su suerte, "para que sus héroes fuesen nuevos héroes al estilo de los de Numancia» (DSC, t. 30, nº 48, 1-6-1918, p. 1327).

88. Una síntesis de estos diez años de guerra en J. M. Piñero Blanca, "La política colonial en Cuba durante la Restauración Borbónica”, en: I. Marín Marina (Coord.), Cuba en el 98, las últimas campañas. Actas XXXVI Curso Aula Militar de Cultura (Cádiz 1998), Sevilla, 2002, 360-361.

89. Francisco Serrano y Domínguez, de la Unión Liberal, había sido capitán general de Cuba y estaba casado con una aristócrata cubana; el progresista Juan Prim, que fue capitán general de Cuba, también estaba casado con una «española de ultramar».

90. J. A. Piqueras Arenas, “La cuestión cubana, de la Revolución Gloriosa a la Restauración”, en: R. Serrano García (Dir.), España, 1868-1874. Nuevos enfoques sobre el Sexenio Democrático, Valladolid, 2002, 169-170. 
En el marco del reformismo colonial se desarrollaron numerosos debates en el Congreso de los Diputados. En uno de ellos, el diputado por Málaga, Francisco Romero Robledo, criticaba al gobierno porque desatendía a los militares que estaban luchando en Cuba y no les recompensaba como se merecían, veía en «aquellos valientes voluntarios y aquel ejército» que luchaban contra los separatistas insurrectos a los «descendientes de los defensores de Sagunto y de Numancia», porque «ni las enfermedades, ni la muerte, ni una guerra de desolación y ruina, ni las inclemencias del tiempo, ni género alguno de penalidades» podía dominarlos; y en un pasado más cercano, eran para él los hijos de Daoíz y Velarde, ${ }^{91}$ los dos oficiales de artillería del cuartel de Monteleón que se sumaron al levantamiento del 2 de mayo de 1808 contra el ejército francés y, sin recibir refuerzos, resistieron allí hasta su muerte.

En los debates en torno al proyecto de ley sobre la abolición de la esclavitud presentado el 28 de mayo de 1870 por Segismundo Moret, ministro de Ultramar, nuevamente Francisco Romero Robledo alude a Sagunto y Numancia en los mismos términos que antes. ${ }^{92}$ Es su respuesta a las afirmaciones que sobre los voluntarios de la isla de Cuba hacen algunos diputados, como que deshonraban el uniforme español y la bandera española, llegando incluso a calificar de insurrectos a los únicos que defendían en la isla la bandera de España, dice nuevamente de ellos «que son dignos descendientes de los defensores de Sagunto y Numancia». ${ }^{93}$ Una afirmación que distaba mucho de ser real, pues los Voluntarios, partidarios del antirreformismo insular propuesto por el gobierno central, se habían convertido en otros insurrectos, de manera que la metrópoli debía poner fin a una doble rebelión. ${ }^{94}$

\section{La libertad de culto}

La libertad de culto fue una de las preocupaciones a las que tuvo que hacer frente Antonio Cánovas del Castillo en los primeros momentos de la Restauración borbónica, ya que estaba en juego que la Santa Sede, presionada por elementos carlistas del Vaticano, reconociese a Alfonso XII; y también que lo hiciese Europa, partidaria de la libertad de cultos. ${ }^{95}$ El resultado fue el artículo 11 de la Constitución de 1876, en el que, para contar con el apoyo de Roma, se reconocía un estado confesional católico y se garantizaba el sostenimiento del culto y del

91. DSC, t. 14, no 247, 24-3-1870, p. 6811.

92. En relación con el contexto histórico y contenido jurídico de esta ley, vid. T. Ushakova, "La Ley Moret. Un intento emblemático de abolición de la esclavitud en las colonias”, en: J. J. González Sánchez - J. M. de Valle Villar (Coord.), Segismundo Moret, presidente del Consejo de Ministros de España. Cuestión social y liberalismo, Madrid, 2016, 42-63.

93. DSC, t. 14, no 308, 17-6-1870, p. 8909.

94. Ma D Domingo Acebrón, "Integrismo y masonería. Los cuerpos de voluntarios en Cuba (18681898)”, en: J. A. Ferrer Benimeli (Coord.), La Masonería española y la crisis colonial del 98. VIII Symposium Internacional de Historia de la Masonería Española (Barcelona 1997), Zaragoza, 1999, 268.

95. F. J. Gómez Díez, "Religión y política en Antonio Cánovas del Castillo”, Estudios eclesiásticos, 73.287, $1998,623$. 
clero; y para contar con el de Europa, sobre todo con el de Prusia e Inglaterra, se toleraban otras religiones, siempre que no se manifestasen públicamente. ${ }^{96}$

La aprobación de este artículo provocó largos y animados debates entre los diputados del Congreso, ya que este sistema de confesionalidad con tolerancia era una solución de compromiso, un tanto ambigua, que había decepcionado tanto a los católicos, como a los liberales radicales. ${ }^{97}$ De todos estos debates nos interesa el que tuvo lugar entre el duque de Almenara Alta, José María Martorell y Fivaller, diputado por Baleares, y Emilio Castelar y Ripoll, diputado por Barcelona. Para el duque de Almenara, como buen conservador ultracatólico, el artículo 11 de la Constitución era un sacrilegio, un error político, un germen de disolución nacional. ${ }^{98}$ Para las autoridades eclesiásticas el catolicismo era inherente a la nación española, y la identificación de patria y religión era una de las ideas clave del pensamiento de la Iglesia española. ${ }^{99}$ De este modo, la unidad católica era la clave de la integridad del territorio de la patria, era vista como «una herencia sagrada» recibida de nuestros antepasados y que se debía conservar para transmitirla a las generaciones venideras; era, por lo tanto, inherente a la raza española. ${ }^{100}$ Eso explica que para el duque de Almenara la religión católica fuese el fundamento del patriotismo del pueblo español que

«por amor a su suelo luchó durante dos siglos con el coloso del mundo antiguo; este pueblo nuestro, en cuyo encadenamiento empleó Roma tanto espacio de tiempo como hubo menester para uncir al carro de su imperio a todas las demás naciones del orbe; este pueblo nuestro, que en los días de mayor pujanza de la fuerza púnica había opuesto a su dominio a la heroica Sagunto coronada de llamas y rodeada de cenizas; este pueblo nuestro, que porfió contra los romanos en Numancia, y cien veces deshizo con las hordas de Viriato la renombrada disciplina de las huestes de la gran República; este pueblo nuestro, para dicha suya, abrió un día sin resistencia sus brazos indomables a los mensajeros de la buena nueva, testigos del triunfo del Calvario o discípulos de los Apóstoles de Jesús». ${ }^{101}$

La respuesta de Castelar al extemporáneo uso que el duque de Almenara hizo del «patriotismo» de Numancia y Sagunto tuvo lugar días más tarde, el 9 de mayo. No se dirigió a él directamente, sino al grupo de jóvenes elocuentísimos que habían invocado las glorias

96. DSC, t. 15, Apéndice noveno al n 97, Título I, Art. 11: «La religión católica, apostólica, romana, es la del Estado. La Nación se obliga á mantener el culto y sus ministros. Nadie será molestado en el territorio español por sus opiniones religiosas, ni por el ejercicio de su respectivo culto, salvo el respeto debido á la moral cristiana. No se permitirán, sin embargo, otras ceremonias ni manifestaciones públicas que las de la religión del Estado».

97. Sobre estos debates y la postura de la Iglesia, vid. C. Robles, Insurrección o legalidad. Los católicos y la Restauración, Madrid, 1988, 121-163. Para una síntesis de los argumentos, a favor y en contra, esgrimidos en el Congreso sobre la unidad religiosa, vid. R. Sánchez Ferriz, "El artículo 11 de la Constitución de 1876", Revista de Estudios Políticos, 15, 1980, 123-137.

98. DSC, t. 15 , no 48, 28-4-1876, p. 972.

99. Id.

100. Id.

101. Id. 
españolas para demostrar que todos estos actos heroicos y el sentimiento de independencia español tenían su origen exclusivamente en la unidad católica. Estos jóvenes habían sido alumnos de Castelar, lo que era una prueba, dijo el propio Castelar, de que los discípulos no aprendían, ni seguían tan fácilmente las doctrinas de sus maestros. ${ }^{102}$ Él no les había enseñado que los dioses adorados por nuestros padres en Numancia y Sagunto fuesen idénticos al dios adorado por nuestros padres en Zaragoza y Gerona, sino que la unidad católica no existió en España hasta al menos Felipe III, antes de este momento había pruebas por todo el país de la coexistencia de cultos. ${ }^{103}$

\section{Las Saguntos y Numancias del s. XIX: Barcelona, Estella y Bilbao}

\section{Barcelona}

El 10 de noviembre de 1869 se discute en las Cortes el dictamen de la comisión sobre la cesión al ayuntamiento de Barcelona de los terrenos sobrantes del derribo de la Ciudadela. ${ }^{104}$ Esta fortaleza militar había sido mandada construir por Felipe V para ejercer un severo control sobre la ciudad de Barcelona, que, tras trece meses de asedio, había caído bajo su poder el 11 de septiembre de $1714 .{ }^{105}$ Para su construcción fueron derribados parte del Barrio de la Ribera, un total de 1.200 casas, y los conventos de San Agustín y Santa Clara; también fueron desalojadas unas 4.500 personas, que, sin recibir indemnización alguna, fueron abandonadas a su suerte. ${ }^{106}$

El ministro de Hacienda, Laureano Figuerola Ballester, estaba a favor de esta donación, y en su discurso compara la resistencia de los catalanes a los Borbones en los sitios de $1705 \mathrm{y}$ 1714 con la que ofrecieron numantinos y saguntinos. En Barcelona, todos los que salían de la plaza y caían prisioneros, eran ahorcados delante de los muros, ${ }^{107}$ y eso explica la comparación de Barcelona con Numancia y Sagunto; pero no con Zaragoza, a la que eclipsa, "porque es más grande la defensa que hizo Barcelona contra los Borbones que la que hizo Zaragoza contra Napoleón». ${ }^{108}$ Para Figuerola no sería legítimo construir aquí cuarteles para el ejér-

102. DSC, t. $15, \mathrm{n}^{\circ} 56,9-5-1876$, p. 1266.

103. Id.

104. Para conocer la suerte de la Ciudadela desde su construcción hasta su derribo, vid. J. M. Muñoz Corbalán, "La Ciudadela de Barcelona. Cuando política y cultura se mezclan", en: Arquitectura y Ciudad, Madrid, 1992, 171-175.

105. Sobre la cuestión de fondo de este conflicto y la relación de Felipe V con Cataluña, vid. J. Albareda i Salvado, "Felipe y Cataluña”, en: Ma A. Bel Bravo et alii (Coord.), El cambio dinástico y sus repercusiones en la España del siglo XVIII, Jaén, 2001, 99-104.

106. En relación con esta alteración del entramado urbano de Barcelona, vid. J. M. Muñoz Corbalán, Verboom. Jorge Próspero Verboon. Ingeniero militar flamenco de la monarquía hispánica, Madrid, 2015, 131141.

107. DSC, t. 14 , no $155,10-11-1869$, p. 4180.

108. DSC, t. 14 , no $155,10-11-1869$, p. 4179. 
cito, tal y como estaba planeado, por dos razones: primero, porque había que recompensar al pueblo de Barcelona por la humillación sufrida «durante este periodo fatal de la dinastía borbónica en España»; y segundo, por el deplorable estado de salubridad de una población que entre 1836 y 1840 había crecido en 30.000 habitantes. ${ }^{109}$

\section{Estella}

El 21 de julio de 1873 el diputado por Navarra, José María Ercazti y Lorente Aguado, pide al Congreso que declare a los «heroicos defensores» del fuerte de Estella dignos de recompensa y que se les indemnice por todos los daños y perjuicios que han sufrido. ${ }^{110}$ Para justificar tal petición relata los acontecimientos que tuvieron lugar en Estella cuando en julio fue sitiada por los carlistas (Tercera Guerra Carlista, 1872 - 1876). ${ }^{111}$ Entonces los liberales se habían atrincherado en el Fuerte de San Francisco y en ningún momento aceptaron la oferta de rendición del bando carlista, a pesar de que fueron llevados hasta allí sus mujeres, hijos y madres para que les suplicasen que se rindiesen.

Los nacionales y la guarnición de Estella, un total de 220 hombres, dice Ercazti, «juraron morir antes que entregarse a semejantes asesinos». ${ }^{112}$ Este comportamiento tan heroico explica el que el diputado navarro mencione a Numancia: «¿Y lo han cumplido? Sí; y tan caballerosamente, y con ánimo tan esforzado, que solamente la heroicidad de Numancia puede compararse á la defensa de estos 220 hombres». ${ }^{113}$

\section{Bilbao}

En los debates sobre los presupuestos del 8 de julio de 1876, Camilo Felipe de Villavaso Echevarría, diputado por Durango, propone una enmienda al art. 17 del presupuesto de ingresos. ${ }^{114}$ Según este artículo, los arbitrios locales establecidos sobre la exportación del hierro quedarían reducidos a la cuarta parte; pero en la propuesta de modificación de este diputado se solicita que se exceptúe de esta rebaja el arbitrio concedido a Bilbao por decreto de 13 de agosto de $1874 .{ }^{115}$ Se trataba de un arbitrio extraordinario de guerra de 50 céntimos de peseta por tonelada de mineral de hierro que se exportaba por la ría y el abra de Bilbao, tanto para la península como para el extranjero. ${ }^{116}$ De la recaudación y administración de este arbitrio se haría cargo el ayuntamiento de Bilbao, y duraría hasta que la ciudad hubiese liquidado

109. DSC, t. $14, \mathrm{n}^{\circ} 155,10-11-1869$, p. $4180-4181$.

110. DSC, t. $15, \mathrm{n}^{\circ} 45,21-7-1873$, p. 814.

111. DSC, t. $15, \mathrm{n}^{\circ} 45,21-7-1873$, p. $813-814$.

112. DSC, t. $15, \mathrm{n}^{\circ} 45,21-7-1873$, p. 813.

113. Id.

114. DSC, t. $15, \mathrm{n}^{\circ} 104,8-7-1876$, p. 2822.

115. DSC, t. $15, \mathrm{n}^{\circ} 104,8-7-1876$, p. $2822 / 2823$.

116. Id. 
su deuda de guerra. ${ }^{117}$ La razón para esta enmienda no era otra que premiar a Bilbao por la defensa que había hecho de las instituciones nacionales durante las insurrecciones carlistas de los años 1870, 1872 y 1873 , y, por supuesto, recompensarla por los gastos que tal proceder le hubiese ocasionado. ${ }^{118}$ El comportamiento de Bilbao, señala Villavaso en su discurso, ha sido comparado por unos con Numancia y Sagunto, y por los más modestos con Zaragoza y Gerona; y aunque Bilbao no afianzó la libertad constitucional, ni trajo la dinastía que ahora rige el país, sí que contribuyó en gran manera a ello. ${ }^{119}$

\section{Conclusiones}

El significado de Sagunto y Numancia en la oratoria parlamentaria es muy claro, y no difiere del que adoptó en otros ámbitos, como en la pintura histórica. Los habitantes de estas dos ciudades, por la heroicidad que habían mostrado en su resistencia a Cartago y Roma, respectivamente, representaban en el ideario del siglo XIX el amor por la libertad y por la independencia, el patriotismo y el rechazo del opresor extranjero y, por encima de todo, el comportamiento heroico. Por eso se convirtieron en el siglo de los nacionalismos en una seña de identidad de la raza española, en la prueba fehaciente de que desde la Antigüedad existía un «carácter español». ${ }^{120} \mathrm{Ni}$ que decir tiene que en este elenco de virtudes tan españolas, no tenían cabida ni los episodios de canibalismo, ni la mención al parricidio, ni la imagen de Sagunto como icono de la fidelidad hacia Roma, aspectos todos ellos mencionados por los autores grecolatinos (vid supra pp. 284 ss.).

Debemos señalar también que los exempla de Numancia tienen un mayor peso en comparación con los de Sagunto. La explicación no es otra que la mayor importancia de la ciudad arévaca en las dos disciplinas que proporcionaron al nacionalismo español emergente sus elementos de cohesión, nos referimos a la Historia y a la Pintura. ${ }^{121}$ Entre las Historias

117. Id.

118. DSC, t. $15, \mathrm{n}^{\circ} 104,8-7-1876$, p. 2823.

119. Id.

120. Era el «retrato ideal de este tipo español natural, anterior a la contaminación foránea» (Álvarez Junco, Mater..., op. cit., 207/ 209-210). Así se explica, por ejemplo, que sean mencionadas en los discursos pronunciados para rebatir los argumentos independentistas de algunos diputados, vid. DSC, t. 17, $\mathrm{n}^{\circ}$ 54, 6-5-1876, p. 1198 y t. 22, n 73, 6-7-1898m p. 2277. En el caso del catalanismo, el diputado regionalista por Gerona, Narciso Pla y Deniel, responde en estos términos a Francisco Macía Llusa, diputado por Lérida y miembro de la fracción autonomista: «Estamos ligados por las leyes de la historia, no solo desde hace cuatro siglos (...), sino desde mucho antes, desde que existimos los unos y los otros; porque yo voy a Sagunto, a la heroica Sagunto, a la que antes con los romanos defendió la España romana contra los cartagineses, con aquel tesón y heroísmo que con el de Numancia consagró la Historia, y veo que Sagunto no es sino tierra de catalanes. (...) Y si estamos unidos por estas leyes geográficas e históricas, que nadie puede desmentir, ¿cómo es posible que todos nosotros juntos, aunque quisiéramos, rompamos estos lazos?» (DSC, t. 31, nº 20, 28-6-1923, p. 637).

121. No hay que olvidar tampoco que en ya las fuentes clásicas el protagonismo de Numancia es mayor que el de Sagunto. 
de España destaca, sin lugar a dudas, la del liberal progresista Modesto Lafuente, Historia general de España desde los tiempos primitivos hasta nuestros días (1850 - 1867), que fue la más usada durante el s. XIX y primeras décadas del s. XX. Es una historia de corte liberal y nacionalista, cuyo objetivo era señalar la esencia de la nación a través de los acontecimientos que se vivieron en ella, como la resistencia a Roma. ${ }^{122}$ Es en el marco de este conflicto donde Numancia aparece retratada como un pueblo de héroes, una

«ciudad indómita, que por tantos años fué el espanto de Roma, que por tantos años hizo temblar á la nación más poderosa de la tierra, que aniquiló tantos ejércitos, que humilló tantos cónsules, y que una vez pudo ser vencida, pero jamás subyugada. Sus hijos perdieron antes su vida que la libertad. Si España no contara tantas glorias, bastaríale haber tenido una Numancia». ${ }^{123}$

Sin embargo, es en el discurso preliminar que precede a la obra, donde el autor deja muy claro que la inmortal Numancia «probó con su ejemplo lo que nadie hubiera creído, á saber, que cabía en lo posible exceder en heroísmo y en gloria á Sagunto». ${ }^{124}$

Esta afirmación de historiador palentino, que sin duda recogía el sentir general, fue difundida por la pintura histórica, el segundo vehículo de expresión de las ideas nacionalistas. Y aunque los pintores se inspiraron en los libros de historia, principalmente en el de Modesto Lafuente, las imágenes de las grandes gestas del pueblo español eran para el público mucho más elocuentes y conmovedoras que los relatos de estos libros. En este género pictórico, uno de los más destacados del siglo XIX, Numancia y Sagunto también tuvieron su sitio, y en ese orden. El primer lienzo que sobre la conquista romana se presentó en una Exposición Nacional fue Numancia de Rafael Enríquez, a este le siguieron otros, entre los que destaca el de Alejo Vera, Los últimas días de Numancia (1881). Por el contrario, Sagunto aparece más tarde como tema en la pintura histórica, y con menos entidad que Numancia, ya que solo en dos cuadros se representa la resistencia de los saguntinos a los ejércitos de Aníbal. ${ }^{125}$

Es evidente, por lo tanto, que la mayor o menor frecuencia de los exempla de Sagunto y Numancia en la oratoria parlamentaria del s. XIX confirmaban el mayor impacto que en

122. A. F. Wulff Alonso, "La Historia de España de D. Modesto Lafuente (1850-67) y la historia antigua”, en: P. Sáez - S. Ordóñez (Eds.), Homenaje al profesor Presedo, Sevilla, 1994, 863-871; Las esencias patrias. Historiografía e historia antigua en la construcción de la identidad española (siglos XVI- XX), Barcelona, 2003, 108-109; López-Vela, “De Numancia...”, op. cit., 2004, 207. Sobre la importancia de la obra de Modesto Lafuente en la historiografía española del XIX, vid. J. Álvarez Junco - G. de la Fuente Monge, El relato nacional. Historia de la historia de España, Barcelona, 2017, 265-283.

123. M. Lafuente, Historia General de España desde los tiempos primitivos hasta la muerte de Fernando VII, Barcelona, 1887, t. 1, p. 93.

124. Lafuente, Historia..., op. cit., t. 1, p. X.

125. Sobre estas representaciones, vid. C. Reyero, La pintura de Historia en España. Esplendor de un género en el siglo XIX, Madrid, 1989, 21-24 (Sagunto) y 30-33 (Numancia); Pérez Vejo, Pintura..., op. cit., 540; J. García Cardiel, "La conquista romana de Hispania en el imaginario pictórico español (1754 - 1894)", CuPAUAM, 36, 2010, 141-143; M. V. Álvarez Rodríguez, "La revisión de los temas de la Antigüedad en la pintura de historia española del siglo XIX: entre la evocación del pasado y la legitimación del poder", El Futuro del Pasado, 1, 2010, 534. 
el imaginario colectivo tuvo la lucha heroica de Numancia en comparación con la de Sagunto. ${ }^{126}$ Así mismo, las gestas de los habitantes de Sagunto y de Numancia estaban al mismo nivel que las de los de Zaragoza o Gerona, pues todas ellas eran ejemplos de la indomable voluntad de lucha de todo un pueblo que defendía su libertad frente al enemigo extranjero. ${ }^{127}$

Por último, en comparación con las etapas precedentes, resulta llamativa la presencia anecdótica de Sagunto y Numancia en los discursos pronunciados en el Congreso durante el reinado de Alfonso XIII y la Segunda República; y que, además, tal circunstancia coincida con el declive de la pintura histórica.

La explicación no es otra que la crisis finisecular en la que se vio sumido el país a finales del XIX, debido a la pérdida de sus últimas posesiones importantes en Ultramar. España vio entonces mermado el poco prestigio internacional que le quedaba y pasó a ser un país de segunda fila, mientras que otros países europeos desarrollaban un nuevo imperialismo que les llevaría a convertirse en importantes potencias. Ya no era un Imperio y, además, había sido derrotada por un país que carecía de una historia gloriosa, de manera que el cliché de las «cualidades patrias» empezaba a tambalearse. ${ }^{128}$ En estos momentos de pesimismo y de crisis surgieron dos tendencias para regenerar la patria, los Tradicionalistas y los Regeneracionistas. Los primeros se refugiaban en las glorias del pasado español para superar esta crisis, como las de Sagunto y Numancia. Sin embargo, se impuso la corriente de los Regeneracionistas, para los que la única vía para salir de esta crisis era iniciar una política de reformas y de modernización del país, pero orientada al bien común. En esta nueva concepción de España ya no había sitio para las grandes gestas que sentaron las bases de la identidad nacional, ahora la identidad nacional debía reafirmarse alrededor de otras glorias o mitos, ${ }^{129}$ además, era necesario olvidar el glorioso pasado y mirar hacia el futuro. ${ }^{130}$ En este nuevo contexto, el comportamiento heroico de Sagunto y Numancia había pasado de moda, al menos por el momento.

126. La supremacía de Numancia se registra también en el vocabulario de la lengua española, nos referimos a los términos «numantinismo», «numantino» o «numantinamente», que definen «la actitud caracterizada por la defensa extrema y tenaz de las propias posiciones o puntos de vista, a menudo en condiciones precarias y con pocas posibilidades de éxito» (DRAE, 22a ed., Madrid, 2001, 1082).

127. En realidad, el paralelismo no es del todo exacto, los sitiados en Zaragoza no se suicidaron, sino que una epidemia de tifus durante el segundo asedio provocó la muerte de muchos de ellos, vid. M. Díaz Gavier, Zaragoza 1808 - 1809. El espíritu de Numancia, Madrid, 2009, 76-78.

128. Álvarez Junco - Fuente Monge, El relato..., op. cit., 21.

129. J. Álvarez Junco, Dioses útiles. Naciones y nacionalismos, Barcelona, 2016, 174.

130. Sobre el nuevo concepto de Historia de España de los regeneracionistas, vid. P. J. Chacón Delgado, Historia y nación. Costa y el regeneracionismo en el fin de siglo, Santander, 2013, 139-162. 
